\title{
O ENSINO DE FILOSOFIA NA RESIDÊNCIA PEDAGÓGICA: UMA EXPERIÊNCIA COM A CONFECÇÃO DE JORNAIS FILOSÓFICOS
}

Teaching Philosophy in the pedagogical residency: an experience with the making of philosophical newspapers

La enseñanza de la filosofía en la residencia pedagógica: una experiencia con la elaboración de periódicos filosóficos

Paulo Sérgio Gomes Soares*1, Cláudia Rezende Monteiro, Leandro de Oliveira Pires, Giovana Miranda Kurovski, Nelzirene Francisca de Sousa, Deusiel Dias da Silva.

${ }^{1}$ Curso de Filosofia. Universidade Federal do Tocantins, Palmas, Brasil

*Correspondência: Coordenação de Filosofia. Av. NS15, Quadra 109N, UFT, Sala 16, CEP 77001-090. PalmasTocantins.e-mail psoares@uft.edu.br

Artigo recebido em 17/03/2020 aprovado em 10/04/2020 publicado em 18/04/2020.

\section{INTRODUÇÃO}

Durante o período de intervenção no Colégio Estadual Girassol de Tempo Integral Rachel de Queiroz, localizado no bairro Aureny III, Palmas-TO, foi implementado o projeto intitulado "Metodologias alternativas para o Ensino de Filosofia", procurando responder aos problemas no processo de ensino e aprendizagem apontados pela preceptora, Professora Cláudia Rezende Monteiro, a saber, que os estudantes entram no Ensino Médio com sérias dificiências de alfabetização, de forma que não conseguem ler, interpretar e escrever satifatoriamente qualquer tipo de texto, situação que se agrava na disciplina de Filosofia, cuja finalidade é desenvolver habilidades e competências que dependem muito de leitura e interpretação dos textos filosóficos.

Outra dificuldade elencada foi a falta de interesse dos estudantes, que não entendem a importância da disciplina na sua formação ou como formação humana e não conseguem visualisar a relação dos conteúdos com a sua própria realidade social, cultural, econômica, ambiental, etc.

Diante desse quadro, muitas propostas de intervenção foram discutidas em reuniões com a equipe de residentes para buscar alternativas e responder pontualmente aos problemas. Em princípio, as dificuldades pareciam ser intransponíveis devido ao pouco tempo de aula dispensada à disciplina, que é apenas de 50 minutos por semana em cada turma.

O objetivo desse artigo é apresentar uma das intervenções desenvolvidas no colégio, bem como os resultados alcançados com a experiência na confecção de jornais filosóficos, idealizado pela preceptora Cláudia Rezende Monteiro, tanto para a formação dos residentes, quanto para a aprendizagem dos estudantes do Ensino Médio. Da mesma forma, apresentar a metodologia, os materiais utilizados e a forma como os residentes prepararam os estudantes do Ensino Médio para a realização das atividades em sala de aula. Todas as etapas da atividade foram registradas em fotos e vídeos.

\section{METODOLOGIAS E MATERIAIS}

A confecção dos jornais se mostrou uma experiência de metodologia alternativa para o Ensino de Filosofia e teve como objetivo buscar melhores resultados no processo de ensino e aprendizagem. Os estudantes do Ensino Médio foram estimulados a 
produzir conhecimentos filosóficos para além do textual, usando a criatividade e a imaginação para disseminar notícias filosóficas para toda a comunidade escolar. Evidentemente, o foco foi ensinar os estudantes a filosofar com vistas em algumas habilidades e competências filosóficas adequadas às séries em que as intervenções aconteceram:

Ler textos filosóficos de modo significativo. Ler, de modo filosófico, textos de diferentes estruturas e registros. Elaborar por escrito o que foi apropriado de modo reflexivo (PCNs, 1999, p. 349).

Ler e escrever são formas de comunicação fundamentais para construir o pensamento reflexivo e o conhecimento filosófico. A confecção dos Jornais Filosóficos teria de atender a esses propósitos. As intervenções aconteceram durante o primeiro semestre de 2019 com 10 turmas da $1^{\text {a }}$ série e 09 turmas da $2^{\text {a }}$ série do Ensino Médio, divididos em grupos de 10 membros por equipe. $\mathrm{Na} 1^{\mathrm{a}}$ série abrangeu os seguintes conteúdos curriculares: Sócrates e o Nascimento da Filosofia; Os Pré-socráticos; Mito e Filosofia / Campo de Investigação Filosófica; Platão e o Mundo das Ideias / O Mito da Caverna. Na 2 ${ }^{\mathrm{a}}$ série, por sua vez, envolveu os seguintes conteúdos: O Contratualismo Thomas Hobbes; O Contratualismo - John Locke; O Contratualismo - Rousseau. Foram confeccionados 38 jornais pelas 10 turmas das $1^{\text {a }}$ séries e 32 jornais pelas 09 turmas das $2^{\mathrm{a}}$ séries, somando um total de 70 jornais confeccionados.

Os jornais filosóficos foram confeccionados a partir de colagens de palavras, frases, imagens, desenhos, etc., para representar o pensamento dos filósofos estudados em pesquisas extraclasse e com apoio do livro didático. Foi pedido aos estudantes que trouxessem para a aula revistas e jornais usados e a escola cedeu materiais como cola, papel A3, tesouras e xerox ${ }^{1}$ para a realização dos trabalhos. Os estudantes foram divididos em grupos de quatro componentes cada e foram estimulados a trabalhar em equipe sob o acompanhamento dos(as) residentes e orientação da preceptora, que auxiliavam nas dificuldades e na confecção dos jornais. A metodologia adotada para desenvolver as atividades foi a sala de aula invertida, uma metodologia ativa que foi adaptada aos interesses e objetivos do Ensino de Filosofia. No caso, os estudantes fizeram pesquisas sobre os temas e filósofos em casa, a partir de diferentes fontes, e participaram de atividades laborais em sala de aula.

Basicamente, o conceito de sala de aula invertida é o seguinte: o que tradicionalmente é feito em sala de aula, agora é executado em casa, e o que tradicionalmente é feito como trabalho de casa, agora é realizado em sala de aula. (BERGMANN; SAMS, 2016, p. 11).

Se o objetivo é a aprendizagem do estudante, ele próprio pode "aprender fazendo" e ser responsável pelo que aprendeu, exercitando o raciocínio num esforço constante por interpretar o pensamento filosófico e expor as ideias de forma criativa. Portanto, a proposta não foi memorizar os conceitos filosóficos, mas dinamizá-los e atualizá-los com a realidade vivida.

\section{RESULTADOS E DISCUSSÃO}

Dois projetos foram desenvolvidos pelos residentes durante as aulas a título de orientação, envolvendo técnicas de comunicação fundamentais para disseminar as notícias filosóficas durante a confecção dos jornais. O projeto "Filosofia do Nariz" trabalhou o riso a partir do pensamento do filósofo francês Henri-Louis Bergson (1859-1941), entendendo que o riso possui uma função social e

\footnotetext{
${ }^{1}$ Custos: duas resmas de folha $\mathrm{A} 3=\mathrm{R} \$ 90,00$; dez tesouras $=\mathrm{R} \$ 48,90$; um litro de cola branca $=\mathrm{R} \$ 13,40$; três unidades de cordão = R\$14,60; e, 360 cópias (xerox).
} 
educativa. Todos os jornais tinham quadrinhos com situações de humor e crítica.

Da minha experiência como palhaça e professora de circo surgiu a ideia de utilizar o riso como ferramenta para despertar o interesse dos alunos nas atividades (Relatório da residente Giovana Miranda Kurovski).

O projeto "A aplicação das regras do Método de Descartes na Geometria" (Relatório do residente Leandro de Oliveira Pires) tratou da geometria para explicar a distribuição dos conteúdos e informações na folha formato A3, de maneira que deixasse de ser folha e se tornasse um veículo de comunicação. Conforme o filósofo e matemático alemão Georg C. Lichtenberg (1742-1799), basta seguir as regras do método cartesiano para matematizar as situações e objetos do cotidiano; os estudantes aprenderam a ocupar os espaços para confeccionar os jornais, colocando cada informação em seu devido lugar e deixando-as atraentes aos leitores.

Em termos de avaliação, cada equipe foi avaliada pela forma como interpretou o pensamento filosófico nos jornais e a atividade gerou uma nota bimestral, contribuindo com a elevação das notas de estudantes que não conseguiam atingir a média com as avaliações tradicionais - meramente escritas.

\section{CONCLUSÃO}

A confecção dos jornais despertou o interesse e a participação dos estudantes, que conseguiram entender alguns aspectos importantes das teorias filosóficas e apresentaram melhoras na leitura, interpretação e escrita de textos filosóficos.

As melhorias foram gradativas com os alunos do Ensino Médio. À medida que os residentes se envolviam com as aulas e com os alunos, o processo de interação entre eles favorecia para um maior envolvimento nas atividades propostas. A participação dos residentes motivava os alunos nas discussões e nas atividades (Relatório da Preceptora Cláudia Rezende Monteiro).

No que tange à formação de professores, vimos tudo o que foi aprendido no processo de formação acadêmica ser aproveitado durante as intervenções, ou seja, houve uma conformação entre a teoria e a prática, entre a postura acadêmica e a postura educadora dos residentes. Acreditamos que o Programa Residência Pedagógica contribuiu muito para rever as atividades na disciplina Estágio Supervisionado, considerando as significativas melhoras no processo de formação de professores advinda do contato direto e cotidiano dos residentes com os professores - sendo tratados como professores.

\section{AGRADECIMENTO}

Agradecemos à preceptora, Professora. Cláudia Rezende Monteiro, e a toda a equipe gestora do CEGTI Rachel de Queiroz pela receptividade e apoio nas atividades e pela disposição em participar do programa, acreditando nessa parceria entre a escola e a universidade.

Todos os autores declararam não haver qualquer potencial conflito de interesses referente a este artigo.

\section{REFERÊNCIAS}

BERGMANN, J.; SAMS, A. Sala de aula invertida: uma metodologia ativa de aprendizagem. Trad. Afonso Celso da Cunha Serra. $1^{\text {a }}$ ed. Rio de Janeiro: LTC, 2016.

BRASIL. Parâmetros Curriculares Nacionais: PCNs Ensino Médio. Ministério da Educação, Secretaria de Educação Média e Tecnológica. Brasília: MEC, 1999.

COTRIM, G.; FERNANDES, M. Fundamentos de

Filosofia. 2. ed. São Paulo: Saraiva, 2013. 